\title{
The point mutation UCH-L1 C152A protects primary neurons against cyclopentenone prostaglandin- induced cytotoxicity: implications for post-ischemic neuronal injury
}

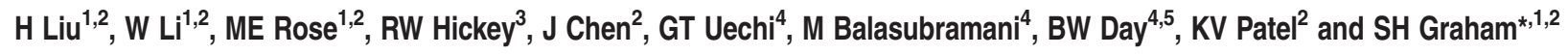

Cyclopentenone prostaglandins (CyPGs), such as 15 -deoxy- $\Delta^{12,14}$-prostaglandin $J_{2}$ (15dPGJ2), are reactive prostaglandin metabolites exerting a variety of biological effects. CyPGs are produced in ischemic brain and disrupt the ubiquitin-proteasome system (UPS). Ubiquitin-C-terminal hydrolase L1 (UCH-L1) is a brain-specific deubiquitinating enzyme that has been linked to neurodegenerative diseases. Using tandem mass spectrometry (MS) analyses, we found that the C152 site of UCH-L1 is adducted by CyPGs. Mutation of C152 to alanine (C152A) inhibited CyPG modification and conserved recombinant UCH-L1 protein hydrolase activity after $15 \mathrm{dPGJ} 2$ treatment. A knock-in (KI) mouse expressing the UCH-L1 C152A mutation was constructed with the bacterial artificial chromosome (BAC) technique. Brain expression and distribution of UCH-L1 in the KI mouse was similar to that of wild type (WT) as determined by western blotting. Primary cortical neurons derived from KI mice were resistant to $15 \mathrm{dPGJ} 2$ cytotoxicity compared with neurons from WT mice as detected by the WST-1 cell viability assay and caspase-3 and poly ADP ribose polymerase (PARP) cleavage. This protective effect was accompanied with significantly less ubiquitinated protein accumulation and aggregation as well as less UCH-L1 aggregation in C152A KI primary neurons after 15dPGJ2 treatment. Additionally, 15dPGJ2induced axonal injury was also significantly attenuated in KI neurons as compared with WT. Taken together, these studies indicate that UCH-L1 function is important in hypoxic neuronal death, and the $\mathrm{C} 152$ site of $\mathrm{UCH}-\mathrm{L} 1$ has a significant role in neuronal survival after hypoxic/ischemic injury.

Cell Death and Disease (2015) 6, e1966; doi:10.1038/cddis.2015.323; published online 5 November 2015

Ubiquitin C-terminal hydrolase $L 1$ is a multifunctional protein that is highly expressed in neurons throughout brain. ${ }^{1}$ UCH-L1 closely interacts with proteins of the neuronal cytoskeleton and may have an important role in axonal transport and maintaining axonal integrity. ${ }^{2,3} \mathrm{UCH}-\mathrm{L} 1$ regulates synaptic function and long-term potentiation (LTP) under normal and pathological conditions and may be involved in memory function. ${ }^{4}$ Mutations and altered function of UCH-L1 have been associated with neurological diseases including Parkinson's (PD) and Alzheimer's (AD) diseases and early onset neurodegeneration involving white matter. $^{2-7}$ However, the role of UCH-L1 function in cerebral ischemic injury and recovery has not been thoroughly investigated.

Cyclopentenone prostaglandins (CyPGs) are the reactive metabolites of prostaglandins containing a carbonyl moiety that may covalently modify cysteine in a variety of proteins. ${ }^{8-10}$
CyPG concentration is dramatically increased in ischemic brain. ${ }^{11}$ CyPGs such as 15dPGJ2 disrupt the ubiquitinproteasome system (UPS), resulting in accumulation and aggregation of ubiquitinated $(\mathrm{Ub})$ proteins and neuronal cell death. ${ }^{12,13}$

$\mathrm{UCH}-\mathrm{L} 1$ is a target of CyPG modification. ${ }^{13-15}$ In the current study, mass spectrometry (MS)/MS was used to determine that cysteine 152 is the binding site of the CyPG 15dPGJ2 to $\mathrm{UCH}-\mathrm{L} 1$. We then constructed a knock-in (KI) mouse using the bacterial artificial chromosome (BAC) technique with a cysteine to alanine mutation at this 15dPGJ2 binding site on $\mathrm{UCH}-\mathrm{L} 1$. Primary neurons derived from KI and wild-type (WT) mice were used to determine the effect of CyPG binding to UCH-L1 on cell death and disruption of the UPS. These studies address a potential role for modification of $\mathrm{UCH}-\mathrm{L} 1$ by CyPGs and other reactive lipid species in stroke and neurodegenerative diseases.

\footnotetext{
${ }^{1}$ Geriatric Research Educational and Clinical Center, VA Pittsburgh Healthcare System, Pittsburgh, PA, USA; ${ }^{2}$ Department of Neurology, University of Pittsburgh School of Medicine, Pittsburgh, PA, USA; ${ }^{3}$ Department of Pediatrics, University of Pittsburgh School of Medicine, Pittsburgh, PA, USA; ${ }^{4}$ Genomics and Proteomics Core Laboratories, University of Pittsburgh, Pittsburgh, PA, USA and ${ }^{5}$ Department of Pharmaceutical Sciences, University of Pittsburgh School of Pharmacy, Pittsburgh, PA, USA

*Corresponding author: SH Graham, Geriatric Research Educational and Clinical Center, VA Pittsburgh Healthcare System, Research Office Building \#30, Mail Code 151, University Drive, Pittsburgh, 15240 PA, USA. Tel: 412360 2914; Fax: 412360 2377; E-mail: Steven.Graham @va.gov

Abbreviations: $15 \mathrm{dPGJ2}, 15$-deoxy- $\Delta^{12,14}$-prostaglandin $\mathrm{J}_{2}$; AD, Alzheimer's disease; BAC, bacterial artificial chromosome; CyPG, cyclopentenone prostaglandin; DIV, days in vitro; EGFP, enhanced green fluorescence protein; FRT, flippase recognition targets; GAPDH, glyceraldehyde 3-phosphate dehydrogenase; KI, knock-in; LDH, lactate dehydrogenase; LV, lentivirus; MS, mass spectrometry; NS, not significant; PAGE, polyacrylamide gel electrophoresis; PARP, poly ADP ribose polymerase; PBS, phosphate-buffered saline; PD, Parkinson's disease; PFA, paraformaldehyde; RIPA, radioimmunoprecipitation assay; SDS, sodium dodecyl sulfate; SE, standard error; TAT, HIV-1 Trans-activator of transcription; Ub, ubiquitinated; UCH-L1, ubiquitin-C-terminal hydrolase; UPS, ubiquitin-proteasome system; V, vehicle; WST-1, cell proliferation reagent; WT, wild type

Received 05.8.15; revised 21.9.15; accepted 30.9.15; Edited by A Verkhratsky
} 


\section{Results}

C152 of UCH-L1 is the critical site for 15dPGJ2 modification. Our and others' previous work has demonstrated that 15dPGJ2 can modify UCH-L1 on cysteine residues through Michael addition and therefore profoundly alter the protein's folding and functions. ${ }^{14,15} \mathrm{UCH}-\mathrm{L} 1$ has six cysteine residues with $\mathrm{C} 90$ considered as the core for protein hydrolase activity. To explore which cysteine residues in $\mathrm{UCH}-\mathrm{L} 1$ are the primary targets for 15dPGJ2 adduction, Flag-tagged $\mathrm{UCH}$ L1 was overexpressed in the rat primary neurons by lentivirus (LV)-Flag UCHL-WT infection and cells were then incubated with 15dPGJ2 $(20 \mu \mathrm{M})$ for $24 \mathrm{~h}$ before harvest. Flag-tagged UCH-L1 was immunoprecipitated with an anti-Flag antibody and the resulting precipitants were separated by PAGE, digested with trypsin, and subjected to nanoLC-MS and -MS/MS analyses.

One of the peptides from the digest with a retention time range of 56.87-57.07 min was observed in the MS experiment as a doubly charged ion at $m / z=748.36$. This ion yielded the MS/MS spectrum (from an average of six tandem mass spectra) shown in Figure 1a. The fragmentation pattern was consistent with the cysteine-modified tryptic peptide NEAIIQAAHDSVAQEGQC ${ }^{*}$, indicating that $15 \mathrm{dPGJ} 2$ adduction (*) occurred at C152.

As a deubiquitinating enzyme, UCH-L1 hydrolase activity cleaves ubiquitin from a poly-ubiquitinated (Ub) protein. In our previous report, 15dPGJ2 modification of UCH-L1 abolished the protein's hydrolase activity. ${ }^{14}$ To examine whether the C152A mutation preserves hydrolase activity after incubation with 15dPGJ2, an in vitro hydrolase activity assay was performed using recombinant UCH-L1 WT and mutant C152A proteins with ubiquitin-AMC, a substrate that fluoresces when hydrolyzed by UCH-L1. Recombinant proteins were incubated with $12.5 \mu \mathrm{M} 15 \mathrm{dPGJ} 2$ and hydrolase activity was measured at 0-12 min after the addition of ubiquitin-AMC. As shown in Figure 1b, treatment with 15dPGJ2 decreased hydrolase activity in both WTand C152A recombinant UCH-L1 protein. However, this reduction was attenuated in mutant UCH-L1 C152A protein compared with WT, suggesting that the mutation preserves some protein function after insult by 15dPGJ2.
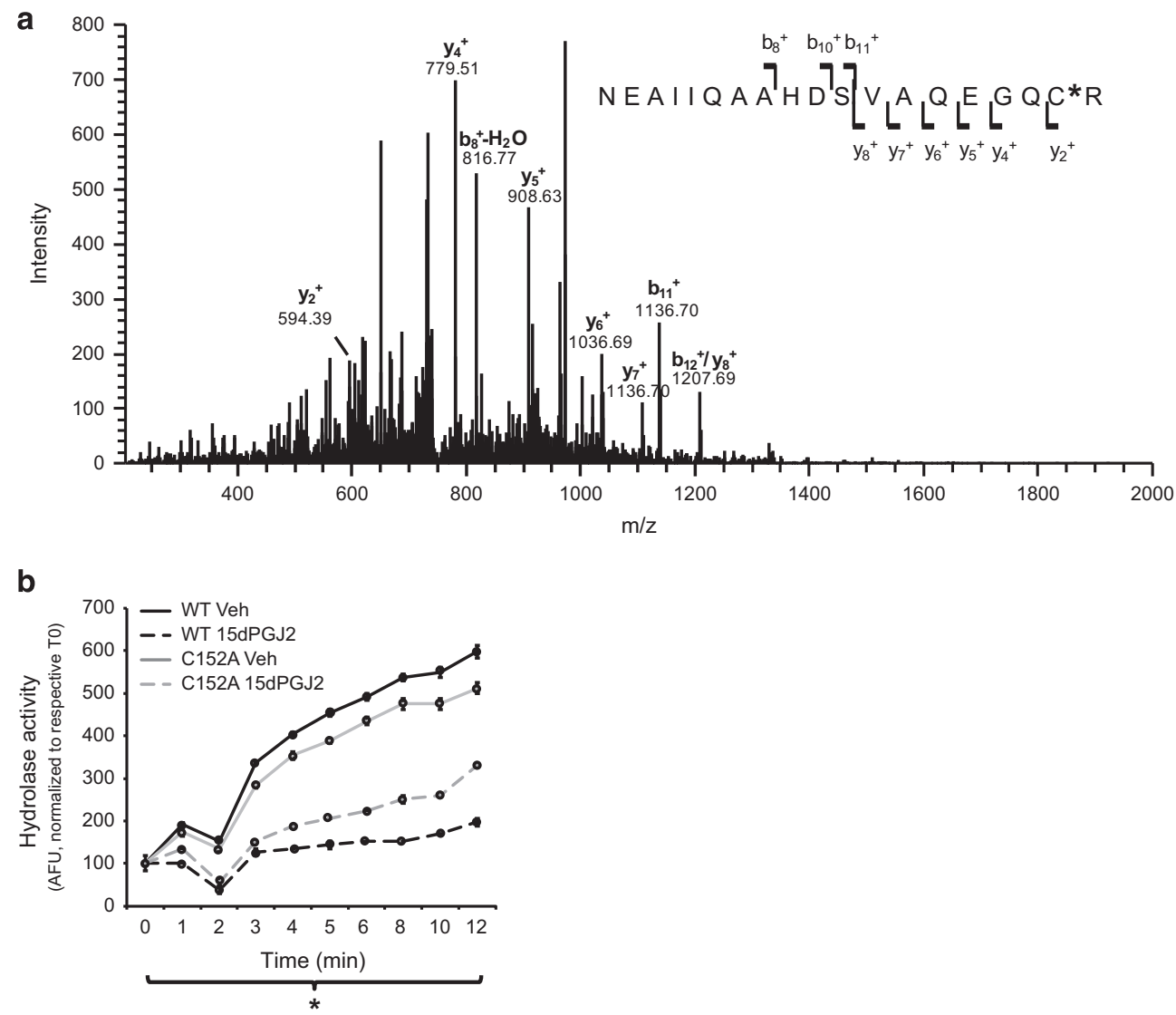

Figure 1 Adduct formation by 15dPGJ2 with cysteine152 is associated with decreased UCH-L1 hydrolase activity. (a) MS/MS spectrum of a tryptic fragment derived from Flag-tagged UCH-L1 expressed in primary neuronal cells following incubation with 15dPGJ2. Schematic representation of the amino-acid sequence, fragment ions, and the corresponding $\mathrm{m} / \mathrm{z}$ values for the cysteine-modified tryptic peptide NEAlIQAAHDSVAQEGQC ${ }^{*} \mathrm{R}$. 15dPGJ2 adduction (*) is shown to occur at C152. The spectrum was from an average of six tandem mass spectra from the doubly charged peptide ion at $\mathrm{m} / \mathrm{z} 748.36$ observed as eluted from $\mathrm{C} 18$ nanoLC separation with a retention range of 56.87-57.07 min. (b) Hydrolase activity in recombinant wild-type (WT) and mutant UCH-L1 C152A (C152A) proteins after incubation with $12.5 \mu \mathrm{M} 15 \mathrm{dPGJ} 2$ for $2 \mathrm{~h}$ measured at $0-12$ min post substrate addition. Data are in arbitrary fluorescence units (AFUs) normalized to their respective time 0 and are expressed as means \pm S.E. $n=2$ per group. ${ }^{*} P<0.05$ between recombinant UCH-L1 C152A and WT 15dPGJ2-treated groups using repeated measures ANOVA with Bonferroni post hoc testing 
Overexpression of UCH-L1 C152A protects rat primary neurons against 15dPGJ2-induced cell toxicity. To test the effect of the UCH-L1 C152A mutation on 15dPGJ2induced primary neuron injury, a series of lentiviral vectors was constructed to infect and overexpress WT UCH-L1 or mutant UCH-L1 C152A in primary neuronal cells. Cells were infected with flag-tagged LV-UCH-L1 WT or LV-UCH-L1 C152A (C152A) at 2 days in vitro (DIV2), and then treated with $5 \mu \mathrm{M} 15 \mathrm{dPGJ} 2$ or vehicle for $48 \mathrm{~h}$. Cell death was measured by lactate dehydrogenase (LDH) assay. As shown in Figure 2a, 15dPGJ2 significantly induced primary neuronal cell death and this toxic effect was attenuated by the overexpression of the UCH-L1 C152A mutation. To analyze the distribution of overexpressed $\mathrm{UCH}-\mathrm{L} 1$, a separate cohort of cells was prepared identically and fixed with paraformaldehyde (PFA) followed by immunocytochemistry with anti-flag antibody. UCH-L1 particle sizes were measured using ImageJ software (National Institutes of Health) and were divided into two categories: large particles measuring over $0.5 \mu \mathrm{M}^{2}$ and small particles measuring less than $0.5 \mu \mathrm{M}^{2}$. The numbers of large and small particles per cell were counted in both $\mathrm{UCH}-\mathrm{L} 1 \mathrm{WT}$ and $\mathrm{C} 152 \mathrm{~A}$ overexpressing primary neurons after $15 \mathrm{dPGJ} 2$ or vehicle treatment.
15dPGJ2-induced UCH-L1 protein aggregation was observed in primary neurons overexpressing WT UCH-L1; this effect was not observed in cells overexpressing the UCH-L1 C152A mutation (Figures $2 b$ and $c$ ).

Construction of the UCH-L1 C152A KI mouse. UCH-L1 is expressed solely in the central nervous system and the reproductive system, making primary neurons an ideal in vitro model in which to investigate the functions of UCH-L1. However, because the protein level of endogenous $\mathrm{UCH}-\mathrm{L} 1$ is very high in primary neurons and because the lentiviral infection rate was limited to $40-50 \%$ in primary neurons, a $\mathrm{KI}$ mouse expressing the UCH-L1 C152A mutation was developed to overcome these obstacles. In collaboration with the University of Michigan Transgenic Core, a targeting vector was constructed and UCH-L1 C152A heterozygous KI male mice were produced on a C57Bl6 background (Figure 3a). These males were backbred to C57Bl6 female mice, and the resulting heterozygous offspring were crossbred to produce homozygous mutant UCH-L1 C152A and WT UCH-L1 lines. No significant differences in growth rate, reproductive abilities, or gross behavior were observed in the $\mathrm{KI}$ mice, as compared with WT. The distribution pattern and
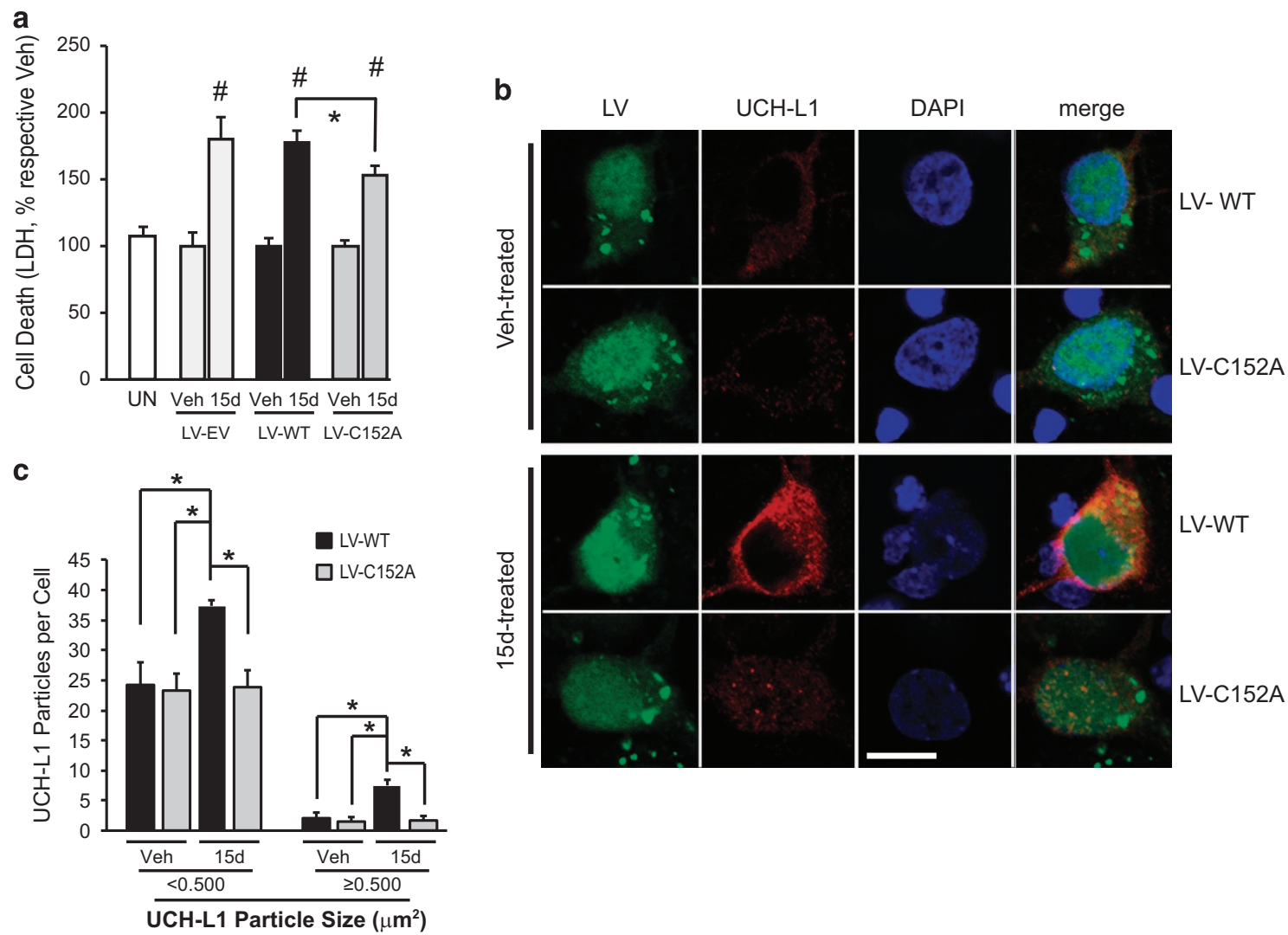

Figure 2 Overexpression of UCH-L1 C152A in rat primary neurons protects cells against 15dPGJ2-induced protein aggregation and cell death. Rat primary neurons were infected with flag-tagged lentivirus (LV)-UCH-L1 wild-type (WT) or LV-UCH-L1 C152A (C152A) at DIV2, then treated with $5 \mu$ M 15dPGJ2 (15d) or vehicle (Veh) for $48 \mathrm{~h}$ at DIV10. (a) Cell death as measured by LDH release, normalized to respective vehicle control. $N=6-12$ per group. ${ }^{*} P>0.05 ;{ }^{\#} P<0.01$ versus UN; Student's $t$-test. (b) Representative photos of LV-infected rat primary neurons after anti-flag immunocytochemistry (red, UCH-L1). Green is EGFP (indicating lentiviral infection) and blue is DAPI nuclear stain. Bar $=10 \mu \mathrm{m}$. Photos taken with an Olympus confocal microscope at 240 x. (c) UCH-L1 particle counts per cell: UCH-L1 particle sizes were measured and counted using NIH ImageJ software (National Institutes of Health). $n=23-25$ per group. ${ }^{*} P<0.05$ using repeated measures ANOVA with Bonferroni post hoc testing. (a and $\mathbf{c}$ ) Data are means \pm S.E. 
a

CONSTRUCTION OF UCH-L1 C 152A KNOCK-IN MOUSE
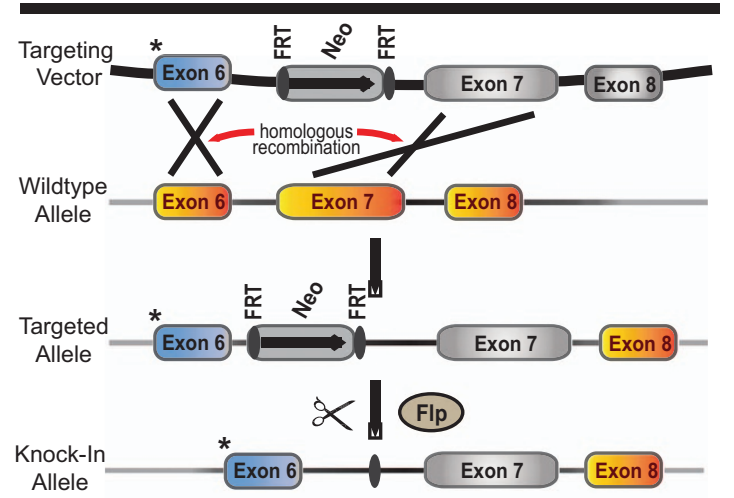

${ }^{*}$ Mutation $\begin{gathered}\text { Cys > Ala } \\ \text { TGT > GCT }\end{gathered}$

FRT - flippase recognition target

Neo - Neomycin cassette; Flp - flippase

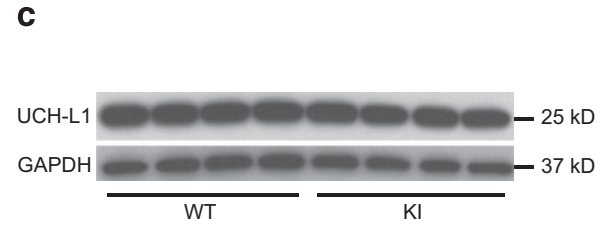

C

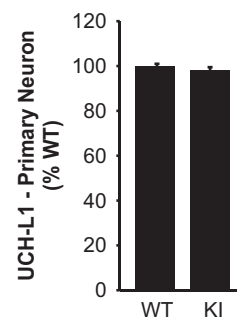

b
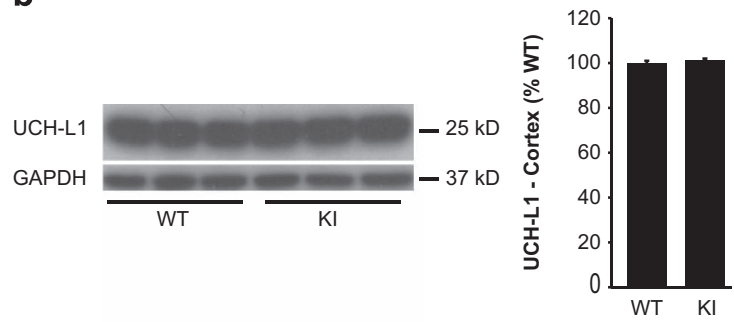

UCH-L1

GAPDH
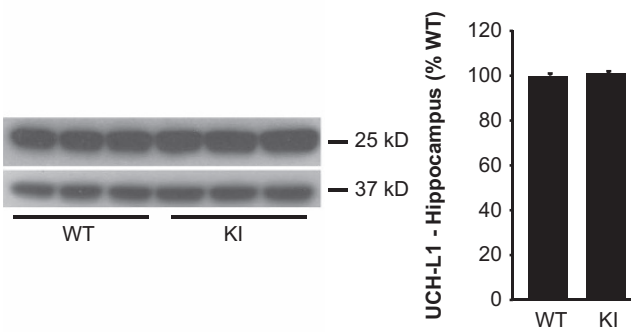

UCH-L1

GAPDH
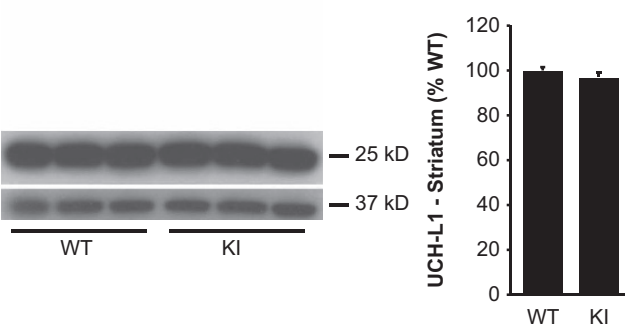

Figure 3 Generation of the UCH-L1 C152A knock-in (KI) mouse. (a) Schematic representation of homologous recombination of DNA fragments producing a point mutation in UCH-L1 converting the 152 cysteine to alanine. (b) UCH-L1 protein expression in UCH-L1 C152A KI and wild-type (WT) mouse brain cortex, hippocampus, and striatum. Brain regions ( $n=3$ per group) were lysed and immunoblotted using anti-UCH-L1 and anti-GAPDH antibodies. Left: immunoblots; right: Graphical densitometric immunoblot analysis. (c) UCH-L1 protein expression in mouse UCH-L1 WT and KI primary neurons produced from UCH-L1 C152A KI and WT mice ( $n=4$ per group). Left: immunoblots; right: Graphical densitometric immunoblot analysis. (b and $\mathbf{c}$ ) Data are means \pm S.E. and normalized to their respective WT groups. GAPDH was used as a loading control

expression levels of UCH-L1 were also similar between WT and $\mathrm{KI}$ mice (Figure $3 \mathrm{~b}$ ). In addition, $\mathrm{UCH}-\mathrm{L} 1$ expression was the same in primary neurons obtained from UCH-L1 C152A $\mathrm{KI}$ mice compared with neurons from WT mice (Figure $3 \mathrm{c}$ ).

Primary neurons from UCH-L1 C152A KI mice are resistant to 15dPGJ2-induced cell death. To assess the effect of the UCH-L1 C152A mutation on cell viability, primary neurons from $\mathrm{C} 152 \mathrm{~A} \mathrm{KI}$ mice were cultured in vitro for 9 days before treatment with $15 \mathrm{dPGJ} 2$ or vehicle at $5-15 \mu \mathrm{M}$ for $24 \mathrm{~h}$. Compared with primary neurons from WT mice, primary neurons produced from UCH-L1 C152A mutant mice were more resistant to 15dPGJ2 cytotoxicity as indicated by significantly higher cell viability after treatment (Figure 4a). Consistent with this finding, protective effects of the UCH-L1 C152A mutation were further confirmed by immunoblotting. When primary neurons were treated with $15 \mathrm{dPGJ} 2$ at 2.5 or $5 \mu \mathrm{M}$ for $24 \mathrm{~h}$, increases in cleaved caspase 3 and poly ADP ribose polymerase (PARP) were observed, suggesting the activation of the apoptosis signal transduction pathway. The activation of caspase 3 and PARP was attenuated in cells produced from UCH-L1 C152A KI mice as compared with WT, indicating that 15dPGJ2-induced apoptosis was significantly inhibited in $\mathrm{KI}$ cells (Figure 4b).

Primary neurons from UCH-L1 C152A KI mice are resistant to 15dPGJ2-induced protein aggregation. 15
dPGJ2-induced protein aggregation was investigated in primary neurons from UCH-L1 C152A KI and WT mice. Primary neurons were seeded on coverslips, and treated with $2.5 \mu \mathrm{M} 15 \mathrm{dPGJ} 2$ or vehicle for $48 \mathrm{~h}$ before fixation, then were immunostained with anti-ubiquitin and anti-UCH-L1 antibodies. Treatment with 15dPGJ2 significantly induced Ub protein and $\mathrm{UCH}-\mathrm{L} 1$ aggregation in WT primary neurons, but this effect was abrogated in UCH-L1 C152A KI cells (Figure 5b). Ubiquitin and UCH-L1 particle sizes were measured and the numbers of large and small particles per cell were counted in both WT and KI primary neurons after $15 \mathrm{dPGJ} 2$ or vehicle treatment. As shown in Figure $5 \mathrm{a}$, the number of ubiquitin aggregates significantly increased after 15dPGJ2 treatment in WT cells but not in $\mathrm{KI}$ cells. Similarly, the number of large UCH-L1 particles per cell was significantly increased in WT cells when treated with $15 \mathrm{dPGJ} 2$ and this effect was not observed in $\mathrm{KI}$ cells.

$\mathrm{Ub}$ protein accumulation and aggregation were also investigated in both WT and KI cells after 15dPGJ2 treatment with immunoblotting. Primary neurons were incubated with vehicle or $15 \mathrm{dPGJ} 2$ at 2.5 or $5 \mu \mathrm{M}$ for $24 \mathrm{~h}$, and the cell lysates were sub-fractionated into radioimmunoprecipitation assay (RIPA)-soluble and -insoluble fractions. PolyUb proteins were detected in each fraction using anti-polyubiquitin antibody. As shown in Figure 5c, 15dPGJ2 treatment induced polyUbprotein accumulation in the RIPA-soluble fraction; however, this effect was significantly decreased in the UCH-L1 

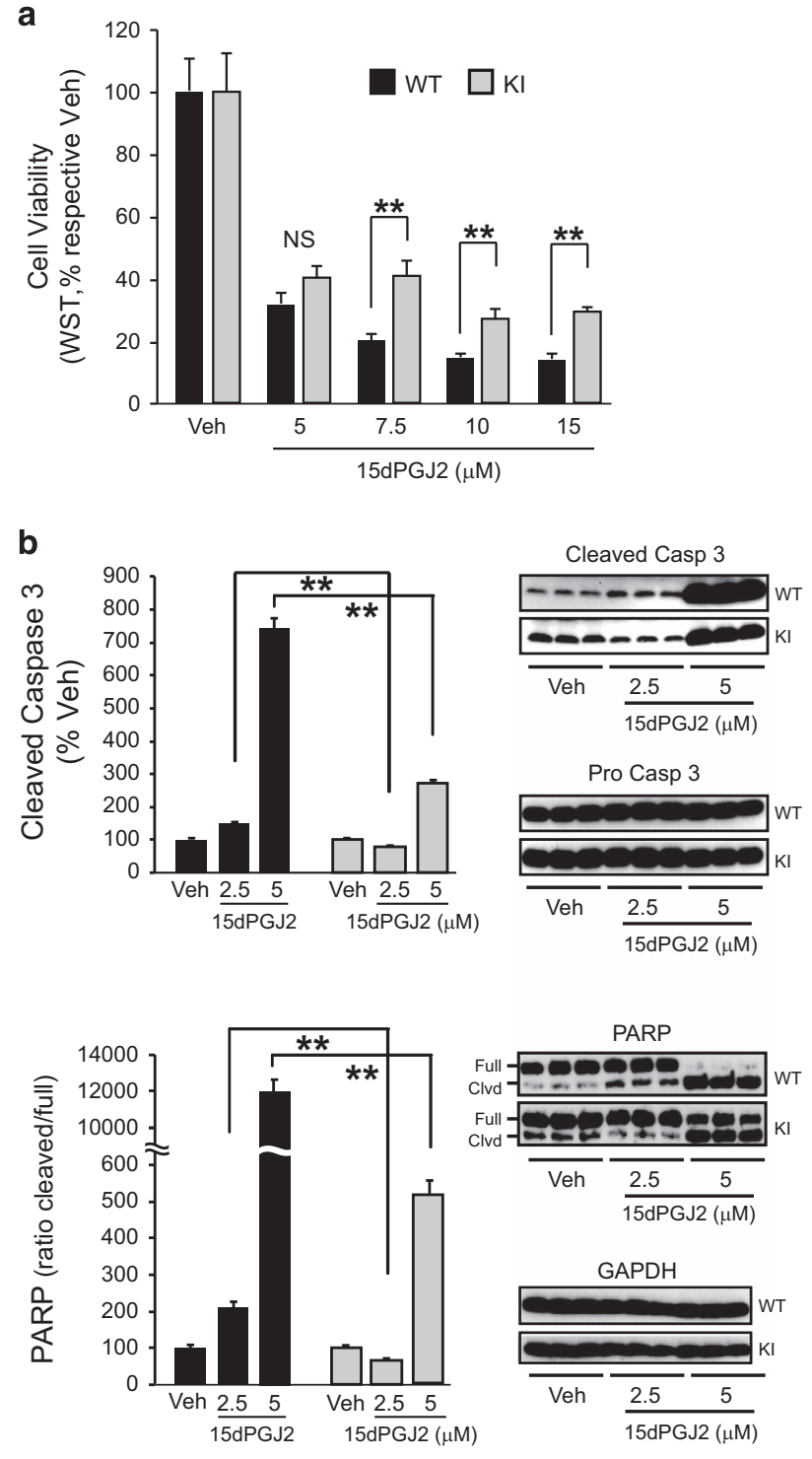

WT $\square \mathrm{KI}$

Figure 4 The UCH-L1 C152A mutation confers protection against 15dPGJ2induced apoptotic cell death. (a and b) UCH-L1 C152A knock-in (KI) and wild-type (WT) primary neurons were treated with 15dPGJ2 or vehicle (DMSO, Veh) for $24 \mathrm{~h}$. (a) Cell viability (WST-1 assay) after treatment with 5-15 $\mu \mathrm{M}$ 15dPGJ2. $N=6$ per group. (b) Immunoblot detection of cleaved caspase 3 (Casp 3), pro Casp 3 (upper group), and PARP (full length: full, cleaved: clvd, lower group) using anti-caspase 3 and anti-PARP antibodies, respectively, after treatment with 2.5 or $5 \mu \mathrm{M} 15 \mathrm{dPGJ} 2$. GAPDH was used as a loading control. Left: Graphical densitometric analysis of immunoblots (right). $N=3$ per group. All: Data are means \pm S.E. and are normalized to their respective vehicle controls. ${ }^{* \star} P<0.01$ versus WT; NS, not significant. Black bar: WT; gray bar: UCH-L1 C152A

C152A KI cells, as compared with the WT cells. Similarly, polyUb-protein aggregation detected in the RIPA insoluble fraction was induced by $15 \mathrm{dPGJ} 2$ in both WT and KI cells but this effect was significantly attenuated in the UCH-L1 C152A $\mathrm{KI}$ cells as compared with the WT cells. Polyubiquitin chains linked from Lys $(K)-48$ of one ubiquitin molecule to the $\mathrm{C}$-terminus of another are the most common ubiquitin linkage. Lys48-linked ubiquitins are abundant in vivo and act as a universal signal for proteins targeted for proteasomal degradation. ${ }^{16} \mathrm{~K} 48$-polyUb is the most abundant ubiquitin linkage type in cells and has an important role in the UPS. Specific K48-polyubiquitin proteins were analyzed by immunoblotting in both WT and UCH-L1 C152A KI cells. Comparable to the results for polyUb protein, K48-polyUb was significantly induced by 15dPGJ2 treatment in both RIPA-soluble and -insoluble fractions and this induction was significantly reduced in UCH-L1 C152A KI cells as compared with WT cells. Taken together, the UCH-L1 C152A mutation attenuated the disruption of the UPS induced by $15 \mathrm{dPGJ} 2$ treatment in primary neurons. In contrast to the K48-polyUb linkage, the K63-polyUb linkage is not associated with proteasome degradation and may have a role in endosome transport and other intracellular functions. Unlike K48-polyUb, 15dPGJ2 treatment significantly decreased K63-polyUb detected by immunoblots in WT primary neurons, and this effect was significantly attenuated in UCH-L1 C152A KI cells (Figure 5d).

Primary neurons from UCH-L1 C152A KI mice are resistant to $15 \mathrm{dPGJ2}$-induced axonal injury. To determine the role of the UCH-L1 C152A mutation in 15dPGJ2-induced neuronal cell axonal injury, primary neurons from $\mathrm{UCH}-\mathrm{L} 1$ C152A KI or WT mice were seeded on coverslips and incubated with 15dPGJ2 $(1.25-5 \mu \mathrm{M})$ for $24 \mathrm{~h}$. The neurites were visualized by immunostaining with anti-neurofilament $L$ antibody. As shown in Figure 6, neuronal neurites were more sensitive to lower doses of 15dPGJ2 than whole cells: neurite injury was observed when cells were treated with $1.25 \mu \mathrm{M}$ 15dPGJ2 in WT neuronal cells compared with $7.5 \mu \mathrm{M}$ $15 \mathrm{dPGJ} 2$ required to induce cell death. 15dPGJ2 treatment significantly decreased the number of intact neurites and increased broken fragments in WT cells in a dose-dependent manner. Neurite damage was significantly reduced in $\mathrm{UCH}$ L1 C152A mutant cells, suggesting that the UCH-L1 C152A mutation preserves axonal integrity against 15dPGJ2induced toxicity.

\section{Discussion}

The major findings of this study are (1) CyPGs such as $15 \mathrm{dPGJ} 2$ adduct the $\mathrm{C} 152$ of $\mathrm{UCH}-\mathrm{L} 1$ and mutation of the $\mathrm{C} 152$ of $\mathrm{UCH}-\mathrm{L} 1$ attenuates the loss of hydrolase activity after 15dPGJ2 treatment; (2) the UCH-L1 C152A mutation decreases 15dPGJ2-induced accumulation and aggregation of UCH-L1 and ubiquitinated proteins in primary neurons; and (3) primary neurons derived from UCH-L1-C152A mutant mice are resistant to cell death and neurite injury induced by treatment with $15 \mathrm{dPGJ} 2$.

MS/MS analysis (Figure 1a) indicates that 15dPGJ2 covalently adducts the $\mathrm{C} 152$ cysteine of $U C H-L 1$. This finding correlates with the observation that CyPG binding to $\mathrm{C} 152$ of $\mathrm{UCH}-\mathrm{L} 1$ by $15 \mathrm{dPGJ} 2$ dramatically alters the $2 \mathrm{D}^{1} \mathrm{H}-{ }^{15} \mathrm{~N} \mathrm{HSQC}$ spectrum of recombinant UCH-L1 protein consistent with unfolding of the enzyme. ${ }^{15}$ The effect of CyPG binding upon protein structure was abolished by mutation of $\mathrm{C} 152$, but not by mutation of other $\mathrm{UCH}-\mathrm{L} 1$ cysteines. ${ }^{15} \mathrm{UCH}-\mathrm{L} 1$ hydrolyzes ubiquitin from poly-ubiquitinated proteins and thus may be a component of the neuronal UPS. ${ }^{4,7,17-19}$ The UCH-L1 C152A 
a

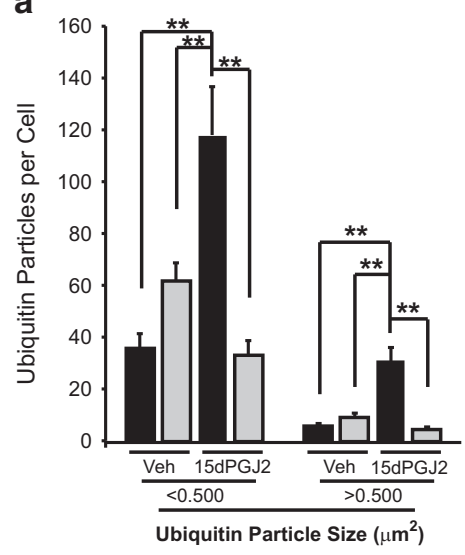

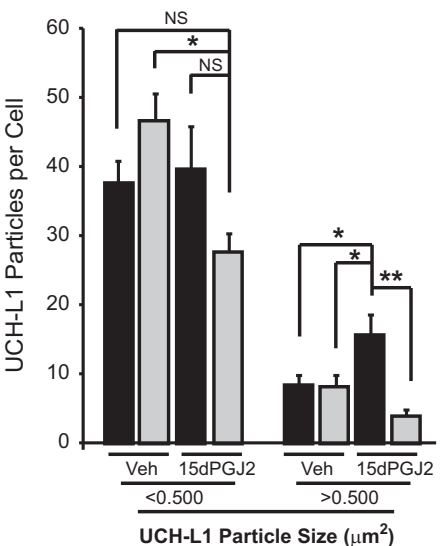

UCH-L1 Particle Size $\left(\mu^{2}{ }^{2}\right)$ b
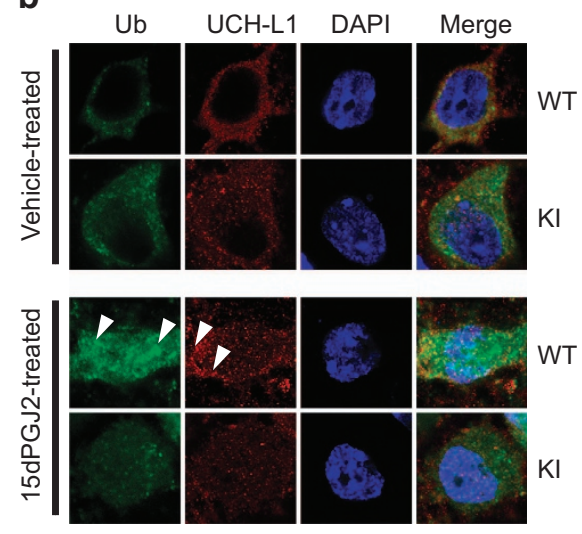

DT $\square$ UCHL1-C152A

C
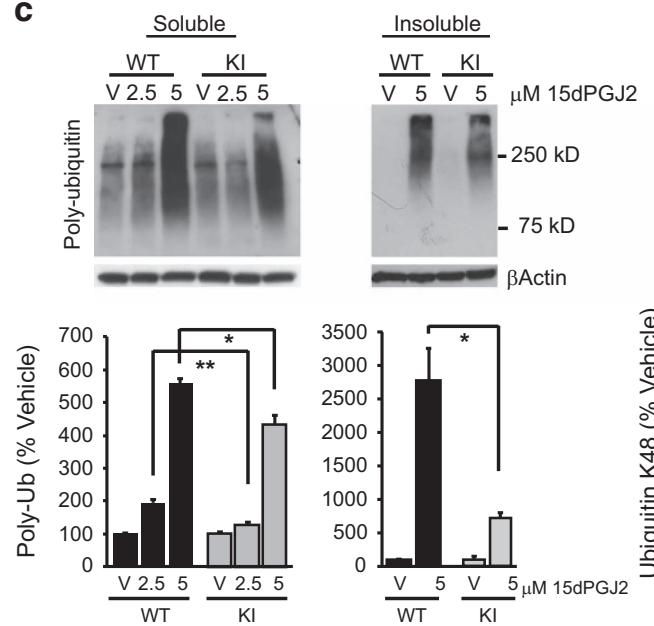
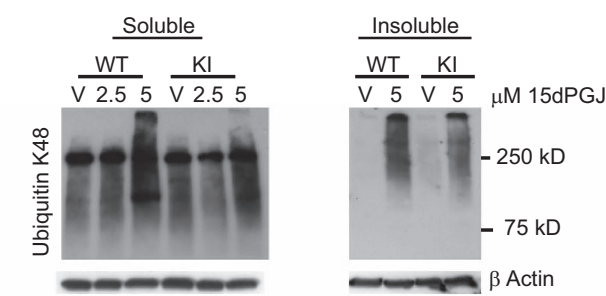

d

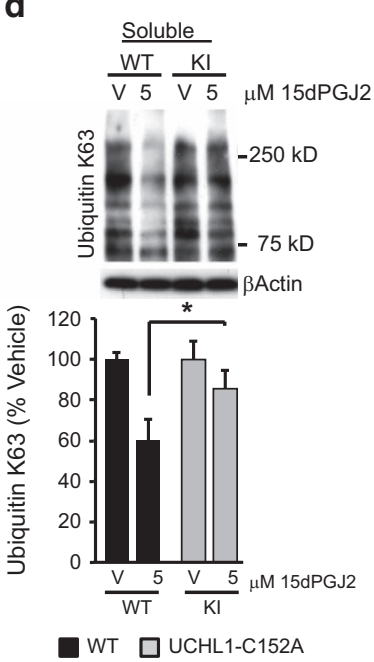

Figure 5 The UCH-L1 C152A mutation attenuates 15dPGJ2-induced protein aggregation in primary neurons. (a and b) Wild type (WT) and UCH-L1 C152A knock-in (KI) primary neurons were treated with $2.5 \mu \mathrm{M} 15 \mathrm{dPGJ} 2$ or vehicle (DMSO, Veh) for $24 \mathrm{~h}$ then immunostained with anti-ubiquitin (green) and anti-UCH-L1 (red) antibodies (a) Ubiquitin (left) and UCH-L1 (right) particles were counted using ImageJ software (National Institutes of Health, $n=23-25$ cells per group). ${ }^{*} P<0.05$; ** $P<0.01$ using one-way ANOVA with Bonferroni post hoc testing. (b) Representative fluoromicrographs of cells measured in (a). Blue is DAPI nuclear stain. Bar $=10 \mu \mathrm{m}$. Arrows indicate aggregates (c) WT and KI cell lysates were prepared from WT and KI primary neurons treated with 15dPGJ2 or Vehicle (V) for $24 \mathrm{~h}$ and fractioned into RIPA-soluble and -insoluble fractions (c) Representative immunoblots detecting poly-ubiquitin (left group) and Ubiquitin K48 (right group) in each fraction. (d) Immunoblot of ubiquitin K63 level in RIPA-soluble fraction. Corresponding densitometric immunoblot analysis is shown below. Data are normalized to their respective vehicle-treated groups. $\beta$-actin was used as a loading control. $N=4$ per group. ${ }^{*} P<0.05 ;{ }^{*} P<0.01$ versus WT. (a and $\mathbf{c}$ ) Data are means \pm S.E.

mutation tempered but did not abolish the decrease in hydrolase activity after incubation with $12.5 \mu \mathrm{M}$ 15dPGJ2. Mutation of $\mathrm{C} 152 \mathrm{~A}$ prevents the unfolding of $\mathrm{UCH}-\mathrm{L} 1$ induced by CyPGs, thus preserving protein function. ${ }^{15}$ But the UCH-L1 hydrolase active site contains a cysteine (C90) that also maybe adducted by 15dPGJ2. Accordingly, mutation of C152 only partially prevents the loss of hydrolase activity produced by CyPGs. The C152A mutation may exert its protective effects through mechanisms in addition to hydrolase activity. UCH-L1 may have other neuron-specific functions including regulation of axon transport and synaptic function. ${ }^{4,20,21}$ Unfolding of UCH-L1 induced by CyPGs may have an important role in disrupting these functions, and these functions may be dependent upon protein-protein interactions with other components of the axon and synaptosome. ${ }^{15}$
CyPGs are reactive lipid species that have been shown to have a wide variety of potential protein targets. ${ }^{8,22-24}$ Their reactive carbonyl group can adduct cysteine in many proteins and have been proposed to have significant biological effects in many signal transduction pathways. ${ }^{25-28}$ CyPGs have been shown to induce cell death in neurons characterized by apoptosis and accumulation of $\mathrm{Ub}$ proteins. ${ }^{10,29-31}$ The results in Figure 4 indicate that the C152A mutation of UCH-L1 significantly reduces 15dPGJ2 toxicity, suggesting that binding of CyPGs to this site is a significant origin of CyPG neuronal toxicity. However, the C152A UCH-L1 mutation affords incomplete protection, thus other targets of CyPGs such as binding to proteasomal proteins may contribute to their toxicity ${ }^{12,32}$ The concentration of $15 \mathrm{dPGJ} 2$ has been measured to increase to an average concentration of $100 \mathrm{nM}$ in ischemic brain, ${ }^{33,34}$ but this 
a 15dPGJ2 $(\mu \mathrm{M})$
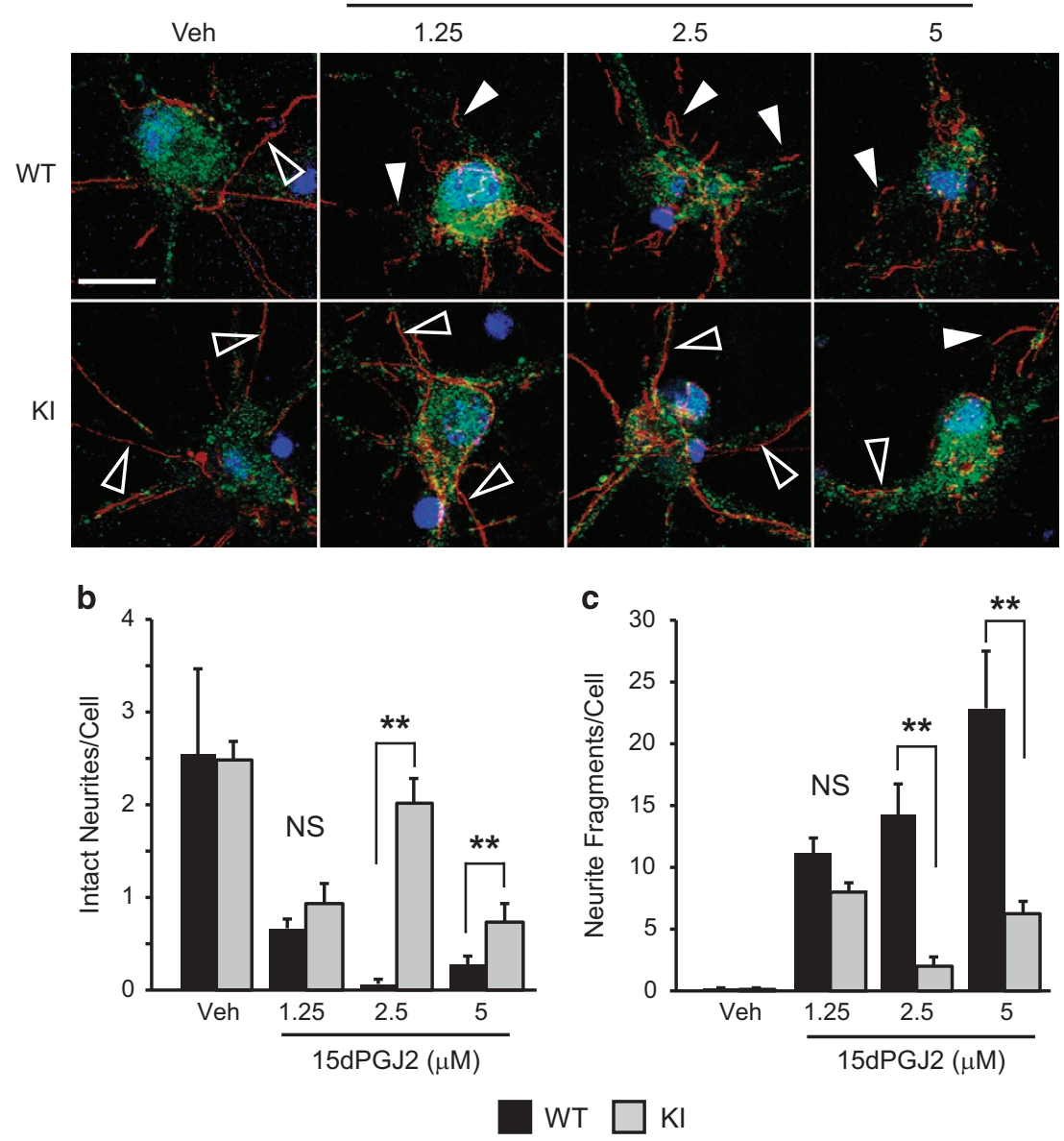

Figure 6 The UCH-L1 C152A mutation protects 15dPGJ2-induced injury to neurites. Wild type (WT) and UCH-L1 C152A knock-in (KI) primary neurons were incubated with $1.25-5 \mu \mathrm{M} 15 \mathrm{dPGJ} 2$ or vehicle (Veh) for $24 \mathrm{~h}$ then immunostained with anti-NeuN (green) and anti-neurofilament $\mathrm{L}$ (red) antibodies. Blue is DAPI nuclear stain. (a) Representative confocal fluoromicrographs taken at $240 \times$. Bar $=20 \mu \mathrm{m}$. (b and c) Intact neurites (outlined arrows) and neurite fragments (solid arrows) were counted in eight fields per group and are normalized to the number of cells examined. Data are means \pm S.E. ${ }^{\star *} P<0.01$ versus WT; NS, not significant

concentration is less than what is reported to produce toxicity in culture. However, whole brain measures of CyPG concentrations may not be reflective of localized intracellular concentrations. Additionally, there are a variety of other reactive lipid species produced under pathological conditions, which also contain reactive carbonyl groups that may interact with the $\mathrm{C} 152$ site. Thus, binding of reactive lipids to the $\mathrm{C} 152$ site may be important to the pathogenesis of ischemic injury and related disorders.

Mutation of the C152 CyPG adduction site of UCH-L1, the site identified with conformational change of the protein with CyPG adduction, afforded protection from 15dPGJ2-induced cell death in primary cortical neurons. The UCH-L1 C152A mutation also attenuated the accumulation of both soluble and insoluble Ub proteins within the neurons. There are increased numbers of aggregates containing $\mathrm{Ub}$ proteins and $\mathrm{UCH}-\mathrm{L} 1$ within the neuron after 15dPGJ2 treatment that are also attenuated by the $\mathrm{C} 152 \mathrm{~A}$ mutation. An increase in soluble Ub proteins may occur when there is either an increase in the number of misfolded proteins to be labeled for proteasomal degradation, or there is dysfunction in the UPS resulting in impaired de-ubiquitination or processing of Ub-tagged proteins by the proteasome. These data suggest that a significant portion of the effect of CyPGs upon accumulation of RIPA-soluble Ub proteins is due to its binding to $\mathrm{UCH}-\mathrm{L} 1$. $\mathrm{UCH}-\mathrm{L} 1$ hydrolyzes ubiquitin from polyUb-tagged proteins allowing the tagged protein to enter the proteasome and recycle free ubiquitin. ${ }^{19}$ Similarly, $\mathrm{UCH}-\mathrm{L} 1$ has been proposed to ligate ubiquitin to proteins; ${ }^{2}$ thus, UCH-L1 may have a major role in the neuronal UPS. The UCH-L1 C152A mutation also attenuated the accumulation of insoluble Ub proteins and specifically K48 polyUb proteins, and decreased the number of intraneuronal particles containing polyUb proteins and UCH-L1. Accumulation of insoluble Ub proteins disrupts multiple protein degradation pathways including both the UPS and autophagy, and results in formation of large protein aggregates. ${ }^{35}$ Binding of CyPGs to $\mathrm{UCH}-\mathrm{L} 1$ produces dramatic structural changes in the molecule and produces aggregation of the protein in vitro. ${ }^{15}$ Accumulation of insoluble protein aggregates occurs in neurodegenerative disease, such as $P D, A D$, and ischemic brain injury. ${ }^{35-37}$ Modification of $\mathrm{UCH}-\mathrm{L} 1$ by $\mathrm{CyPG}$ and other reactive lipids may result in aggregation of $\mathrm{UCH}-\mathrm{L} 1$ and insoluble protein aggregates, and thus could be 
important in the pathogenesis of these and related disorders. $^{38}$

K63-linked Ub proteins were also detected in WT and KI cells by immunoblotting (Figure $5 \mathrm{~d}$ ). Unlike K48-ubiquitin linkage, it has been suggested that K63 ubiquitin linkage does not have a significant role in the UPS, but rather is important in endosomal trafficking, DNA damage response, and intracellular signal transduction. ${ }^{39,40} \mathrm{~A}$ recent report has demonstrated that impairment of K63-polyUb response during oxidative stress affects polysome stability and protein expression, rendering cells more sensitive to stress. ${ }^{41}$ Twenty-four hour treatment with 15dPGJ2 significantly decreased the K63polyUb level in WT primary neurons, and this effect was significantly attenuated in UCH-L1 C152A KI cells. Therefore, besides the effects on the proteasome system, the UCH-L1 C152A mutation may protect primary neurons against CyPG insults through other mechanisms such as protection against oxidative stress.

While UCH-L1 may have a role in the neuronal UPS, there are other enzymes expressed in brain such as UCH-L3 with much higher hydrolase activity that are known to be major constituents of the UPS in other cell types. ${ }^{42} \mathrm{UCH}-\mathrm{L} 1$ is selectively expressed in neurons, suggesting that it has a neuron-specific function. UCH-L1 interacts with cytoskeletal and synaptic proteins, and thus may have an important role in axonal transport and synaptic function. ${ }^{7,43-46}$ Humans with mutations in $\mathrm{UCH}-\mathrm{L} 1$ have been reported to have extensive white-matter abnormalities. ${ }^{5}$ Furthermore, UCH-L1 activity modulates LTP in hippocampus and is deficient in a mouse model of AD. ${ }^{4,47}$ These data indicate that neuronal processes are more sensitive to 15dPGJ2-induced injury than the neuronal cell body and that the UCH-L1 C152A mutation protects neuronal processes from the toxic effects of CyPGs. Thus, UCH-L1 may have an important role in maintaining the structure and function of axons and dendrites.

These results demonstrate that the binding of CyPGs and other reactive lipid species may have a role in the pathogenesis of ischemia and neurodegenerative disease. Gong et al. ${ }^{4}$ have shown that it is feasible to construct a HIV-1-trans-activating (TAT) domain fused UCH-L1 protein (TAT-UCH-L1). TAT-UCH-L1 proteins cross the blood brain barrier, transduce neurons, and improve memory function in AD mouse models. Additional modification of the $\mathrm{C} 152$ by the TAT-UCH-L1 protein may confer additional potency and stability to these proteins enhancing their therapeutic potential. Furthermore, conventional drugs that compete for the binding of the reactive lipids to the C152 site could be designed.

In summary, CyPGs and other reactive lipids produced in cerebral ischemia may bind to $\mathrm{UCH}-\mathrm{L} 1$ and disrupt its structure and function, and the metabolism of $\mathrm{Ub}$ proteins in the neuron. The resultant accumulation of insoluble protein aggregates may produce pathogenic effects similar to those seen in stroke and neurodegenerative diseases. Neuronal processes are particularly sensitive to CyPG toxicity mediated through CyPG binding to UCH-L1. Binding of CyPGs and other reactive lipid species to $\mathrm{UCH}-\mathrm{L} 1$ may be important in the pathogenesis of stroke and neurodegenerative disease, and is a potential target for future therapeutic interventions.
Materials and Methods

Experimental procedures. Animal studies were performed with the approval of the University of Pittsburgh Institutional Animal Care and Use Committee and conducted according to the National Institutes of Health Guide for the Care and Use of Laboratory Animals. Animals were housed in a temperature- and humiditycontrolled environment with $12 \mathrm{~h}$ light cycles and free access to food and water.

Reagents and antibodies. 15dPGJ2 was purchased from Cayman Chemical (Ann Arbor, MI, USA). Antibody sources were as follows: mouse monoclonal anti-mono- and poly-ubiquitinated proteins antibody (clone FK2) and anti-polyubiquitinated proteins antibody (clone FK1) were from Enzo Life Sciences (Plymouth Meeting, PA, USA). Monoclonal anti-ubiquitin antibody was from Covance (Berkeley, CA, USA) and anti-ubiquitin Lys48-specific antibody was from Millipore (Temecula, CA, USA), anti-ubiquitin Lys63-specific antibody was from Abcam (Cambridge, MA, USA); anti-PARP, anti-caspase-3, and anti-Neurofilament-L antibodies were from Cell Signaling (Boston, MA, USA); anti- $\beta$-actin antibody and anti-UCH-L1 antibody were from Sigma-Aldrich (St Louis, MO, USA); anti-NeuN antibody was from Millipore; and anti-GAPDH antibody was from Ambion (Grand Island, NY, USA). Cy3- and Alexafluor 488-conjugated secondary antibodies were from Jackson Immunoresearch Lab (West Grove, PA, USA). Ultra performance liquid chromatography organic solvents and water were from VWR (West Chester, PA, USA). The lentiviral expression vector, pLVX-IRES-ZsGreen1 vector, and Lenti-X HTX concentrator and packaging system were purchased from Clontech Laboratories (Mountain View, CA, USA). WST-1 cell proliferation assay kit and Lenti-X 293 T cell line were purchased from Clontech.

Plasmid constructs. The DNA sequence encoding full-length rat UCH-L1 WT was amplified by PCR, and cloned into pET22b vector (Novagen, San Diego, CA, USA), using Ndel and Xhol restriction sites. A UCH-L1 point mutation substituting alanine for cysteine (UCH-L1 C152A) was introduced by PCR. Constructs were confirmed by sequencing. For lentiviral expression vector construction, UCH-L1 WT or UCH-L1 C152A cDNA was inserted into pLVX-IRES-ZsGreen1 vector with Xhol and BamHI restrictive sites to generate lenti-UCH-L1 WT or lenti-UCH-L1 C152A. ${ }^{24}$ This vector expresses UCH-L1 WT or its mutant C152A and the green fluorescent protein ZsGreen from a bicistronic mRNA transcript, allowing ZsGreen to be used as an indicator of transduction. The resulting constructs were confirmed by DNA sequencing. To generate infectious lentiviral particles, Lenti-X $293 \mathrm{~T}$ cells were transfected with the lenti-UCH-L1 WT and KI vectors, or empty lentiviral vector together with Lenti-X packaging mix using XFect (Clontech) following the manufacturer's instructions. Lentiviral particles were then collected, concentrated, and purified. UCH-L1 C152A and WT lentiviral titrations were determined with a Lenti-X qRT-PCR titration kit (Clontech).

Expression and purification of recombinant proteins. Plasmids were introduced into Escherichia coli Rosetta (DE3) strains (Novagen) producing $6 x$ His-tagged full-length UCH-L1 WT or the mutant protein UCH-L1 C152A. Protein production was induced by shaking the $E$. coli Rosetta cells in 'overnight express autoinduction system' (Novagen) at 300 r.p.m. for $16 \mathrm{~h}$, then purified with a His-select column (Sigma-Aldrich) according to the manufacturer's protocol. Protein purity was assessed by SDS-PAGE and Coomassie blue staining. Recombinant UCH-L1 WT and UCH-L1 C152A proteins were further confirmed by immunoblotting.

Protein in-gel digestion and tandem MS. Rat primary neurons were infected with LV-Flag UCHL-WT at DIV2 to overexpress Flag-tagged UCH-L1-WT. Cells were then incubated with $15 \mathrm{dPGJ} 2(20 \mu \mathrm{M})$ for $24 \mathrm{~h}$ at DIV11 before harvest. The cell lysates were immunoprecipitated with an anti-Flag antibody, and the resulting precipitants were subjected to polyacrylamide gel electrophoretic separation, in-gel digestion, and nanoLC-MS and -MS/MS analyses.

The gel was then stained with Coomassie blue, protein bands were excised, minced, and digested with porcine Trypsin Gold (Promega, Madison, WI, USA), as previously described ${ }^{24,48}$ with minor modifications. Peptides extracted from the digested gel bands were analyzed on a Thermo Fisher LTQ Orbitrap Velos (Thermo Fisher, Pittsburgh, PA, USA) connected to a Waters Acquity Ultra Performance Liquid Chromatography (UPLC) system (Waters Corp., Milford, MA, USA) consisting of sample trap (nanoAcuity UPLC trap column, $180 \mu \mathrm{m} \times 20 \mathrm{~mm}, 5 \mu \mathrm{m}$ particle size, Symmetry C18, Waters Corp.) and a C18 column (nanoAcquity UPLC column, $75 \mu \mathrm{m} \times 250 \mathrm{~mm}, 1.7 \mu \mathrm{m}$ particle size, BEH300 C18, Waters Corp.) interfaced with a nanospray ionization source. Solvent $A$ was $0.1 \%$ formic acid in water. Solvent $B$ was $0.1 \%$ formic acid in acetonitrile. Samples were loaded on the sample trap with $1 \%$ 
Solvent $\mathrm{B}$ at a flow rate of $15 \mu \mathrm{l} / \mathrm{min}$ for $1 \mathrm{~min}$. Peptides were then eluted off the column with a 90 -min gradient running at $300 \mathrm{nl} / \mathrm{min}: 5 \% \mathrm{~B}$ for $3 \mathrm{~min}, 5-55 \% \mathrm{~B}$ in $60 \mathrm{~min}, 30-95 \%$ B in $1 \mathrm{~min}, 95 \%$ B for $5 \mathrm{~min}, 95-5 \%$ B in $1 \mathrm{~min}, 5 \% \mathrm{~B}$ for $20 \mathrm{~min}$. All MS spectra were acquired in the Orbitrap detector at a resolution of 60000 in profile mode, while top nine data-dependent MS/MS spectra were yielded by fragmentation of precursor peptide ions using collision-induced dissociation (CID) normalized collision energy setting of $35 \%$ in the ion trap of the LTQ mass spectrometer, then acquired in the Orbitrap at a resolution of 7500 .

Database searches were done with Proteome Discoverer 1.4 against the complete Uniprot human database appended to a contaminant database (88 575 sequences, 35106826 residues) with the Sequest search engine for a trypsin digest with two missed cleavages, three dynamic modifications (oxidation of methionines, carbamidomethylation of cysteines, and 15dPGJ2 adduction of cysteines). The mass tolerance was set at 10 p.p.m. for precursor mass and $0.8 \mathrm{Da}$ for CID fragment ion masses. Peptide identifications were validated using the Percolator algorithm with a $5 \%$ global false discovery rate (FDR). The spectra of 15dPGJ2-adducted peptides were manually inspected.

In vitro hydrolase activity assay. The UCH-L1 hydrolase activity assay was performed as previously described with slight modifications. ${ }^{14}$ Briefly, $2 \mu \mathrm{M}$ UCH-L1 protein was incubated with $12.5 \mu \mathrm{M} 15 \mathrm{dPGJ} 2$ or vehicle for $2 \mathrm{~h}$ before dilution with UCH-L1 hydrolase buffer. Samples were then mixed with $500 \mathrm{nM}$ ubiquitin-AMC (BostonBiochem, Cambridge, MA, USA). The final concentration for UCH-L1 was $100 \mathrm{nM}$. Free AMC fluorophore was read using a fluorescent plate reader (ex $360 \mathrm{~nm}$, em $460 \mathrm{~nm}$ ).

Primary neuronal cell culture and LV infection. Rat cortical primary neuronal cultures were prepared from E17 fetal rats (Sprague-Dawley, Charles River, Wilmington, MA, USA) as previously described ${ }^{49,50}$ and used for experiments after 9 DIV. Cells were grown in serum-free Neurobasal medium (Invitrogen, Carlsbad, CA, USA) supplemented with B27 and GlutaMAX (Invitrogen). To overexpress UCH-L1 or mutant UCH-L1 C152A in primary neurons, cells were seeded in 96-well plates and lenti-UCH-L1, lenti-UCH-L1 C152A, or empty lentiviral particles were added to the culture medium at $1.2 \times 10^{8}$ particles/well for $18 \mathrm{~h}$. Viral infection was performed at DIV 2, and cells underwent 15dPGJ2 treatment at DIV10. Cell viability and cell death were quantitatively assessed by LDH assay and WST-1 cell viability assay according to the manufacturer's protocols ( $n=6-12$ wells per group).

Construction of the UCH-L1 C152A KI mouse. In collaboration with the University of Michigan Transgenic Core, the BAC technique was used to construct a UCH-L1 C152A KI mouse. ${ }^{51-54}$ Homologous recombination of DNA fragments was used to modify a BAC containing UCH-L1 to produce a point mutation in UCH-L1 that converts the 152 cysteine to alanine (TGT>GCT) within the normal chromosome of the mouse (Figure 3a). In brief, a C57BL/6J mouse genomic clone from the RP23 BAC library was modified to carry the TGT > GCT mutation and a drug selection cassette (PGK-neo) flanked by flippase recognition target (FRT) sites. The drug selection cassette confers resistance to the antibiotic G418. The FLP recombinase enzyme recognizes FRT sites and is used to remove the cassette so that it will not interfere with UCH-L1 C152A gene expression. Thus, the UCH-L1 C152A mutation is transcribed under control of the original physiological promoters and other flanking sequences of the mouse chromosome to faithfully reproduce physiological expression of mutant UCH-L1 C152A. The targeting vector was constructed by gap repair from the BAC and was confirmed by sequencing: (1) the TGT > GCT mutation was correctly positioned in exon 6; (2) the PGK-neo cassette was correctly inserted; (3) both FRT sites were present around the PGK-neo cassette, and the diagnostic Nsi I restriction enzyme site was present on the $3^{\prime}$ side of the $3^{\prime}$ FRT site, permitting the use of Nsi I for the identification of gene-targeted embryonic stem (ES) cells. The vector was then linearized and electroporated into mouse C57BL/6J ES cells. After neomycin selection, Southern blots were performed to identify ES cells having homologous recombination. These ES cells were shipped to Taconic Artemis (Koeln, Germany) and injected into blastocysts to generate heterozygous UCH-L1 C152A KI mice on a C57BI6 background. Male heterozygous UCH-L1 C152A mice were then bred with female C57BI6 mice. Heterozygous offspring were crossed to produce homozygous UCH-L1 C152A and WT UCH-L1 lines. Mouse genotype was identified by genomic DNA extraction and PCR amplification with primers $5^{\prime}$-CGAGGTAATAGAAAATGCTTCTGG-3' and $5^{\prime}$-GAATATGCTCCAAACAGCTTGC-3'. The details of targeting vector, Southern blotting, and genotyping protocols are available upon request. Mouse cortical primary neuronal cultures were prepared from E17 WT and KI fetal mice as described above and used for experiments after 9 DIV.

Fluorescent immunocytochemistry. Primary neurons were seeded on glass coverslips and incubated with 15dPGJ2 or methyl acetate (veh) for $24 \mathrm{~h}$ before fixation with 4\% PFA in phosphate-buffered saline (PBS). Immunocytochemistry using anti-Ub-proteins and anti-UCH-L1 antibodies followed by Alexafluor 488 and DyLight 549-conjugated secondary antibodies was performed, and cells were photographed using an Olympus confocal microscope with FluoView FV1000 software (Olympus, Tokyo, Japan). For particle size counting, cells were photographed at $\times 240$. UCH-L1 particles $<0.5 \mu \mathrm{M}^{2}$ and $\geq 0.5 \mu \mathrm{M}^{2}$ were counted in 23-25 individual cells per group using $\mathrm{NIH}$ ImageJ software (National Institutes of Health, Bethesda, MD, USA). Data were analyzed by a blinded investigator using one-way ANOVA with Bonferroni post hoc testing.

Preparation of detergent-insoluble fraction from cell lysates. The cell lysate detergent-insoluble protein aggregate fraction was prepared as previously described. ${ }^{34}$ In brief, primary neurons were treated with vehicle (methyl acetate) or $15 \mathrm{dPGJ} 2(2.5$ or $5 \mu \mathrm{M})$ for $24 \mathrm{~h}$. Cells were lysed in RIPA lysis and extraction buffer (Pierce, Rockford, IL, USA) containing $25 \mathrm{mM}$ Tris- $\mathrm{HCl}$ (pH 7.6), $150 \mathrm{mM} \mathrm{NaCl}, 1 \%$ NP-40, $1 \%$ sodium deoxycholate, $0.1 \%$ SDS, and protease inhibitor cocktail (Pierce). Cells were incubated with RIPA buffer for 15 min on ice then centrifuged at $16,800 \times g$ at $4{ }^{\circ} \mathrm{C}$ for $15 \mathrm{~min}$. The supernatants were collected and the insoluble pellets were washed twice with cold PBS, and then re-suspended in RIPA buffer containing $0.5 \%$ SDS for $1 \mathrm{~h}$ on ice and sonicated three times for protein solubilization. Protein concentrations were determined by the bicinchoninic acid (BCA) method (Pierce).

Western blotting. Western blotting was performed as previously described. ${ }^{14}$ For caspase-3, PARP, and UCH-L1 detection, cell lysates were resolved on 10 or $12 \%$ SDS-PAGE. After blocking with 5\% non-fat milk in TBS/Tween-20, membranes were incubated with anti-caspase-3, anti-PARP, or anti-UCH-L1 antibodies at $4{ }^{\circ} \mathrm{C}$ overnight. For Ub-protein detection, cell lysates were resolved on a $4-20 \%$ linear gradient polyacrylamide gel (Bio-Rad, Hercules, CA, USA) before incubation with anti-poly-ubiquitinated conjugates, anti-ubiquitin Lys48-specific or anti-ubiquitin Lys63-specific antibodies (1:1000 for all). Blots were washed and the appropriate secondary antibodies applied. Protein signal was visualized with ECL reagents (Pierce). Blots were subsequently stripped and re-probed using anti-GAPDH or $\beta$-actin antibodies for verification of equal protein loading. Brain cortex, hippocampus, and striatum were dissected from male 12-week-old WT and KI mice ( $n=4$ per group) and rapidly frozen on dry ice until homogenization with T-PER tissue protein extraction reagent (Pierce) and protein measurement. Equal amounts of protein were loaded for SDS-PAGE and immunoblotted using anti-UCHL1 antibody as described above.

Axonal injury assay. Primary neurons from WT or UCH-L1 C152A KI mice were seeded onto L-poly D-lysine-coated glass coverslips. 15dPGJ2 treatment was performed on DIV11, and cells were fixed with 4\% PFA in PBS at different time points $(8,16$, and $24 \mathrm{~h}$ post treatment). After permeabilization with blocking buffer ( $2 \%$ BSA, $1 \%$ fish skin gelatin and $0.02 \%$ saponin in PBS) for $1 \mathrm{~h}$ at room temperature, cells were immunostained with anti-Neurofilament-L antibody $(1: 100$, Cell Signaling Technology \#2837, Danvers, MA, USA) and Alexafluor 488conjugated secondary antibody sequentially and photographed using a confocal microscope (Olympus, Tokyo, Japan). Image acquisition and analysis was performed on $\times 60$ images randomly taken from two coverslips for each treatment condition per genotype ( $n=8$ fields per group). Quantification of axon degeneration was performed by a blinded investigator as previously described. ${ }^{55,56}$ The axon/ neurite outgrowth was evaluated based on morphological characteristics: (1) intact: length of neurite outgrowth $>2 x$ the length of the soma and (2) fragmented: isolated neurite swellings. The numbers of intact neurites and neurites fragments were normalized to the number of neurons examined.

Statistical analysis. Data are expressed as means \pm S.E. and were analyzed using one-way ANOVA with Bonferroni or Dunnett's post hoc testing where appropriate using SPSS software (IBM Corporation, Armonk, NY, USA). Results were considered to be significant when $P<0.05$.

\section{Conflict of Interest}

The authors declare no conflict of interest. 
Acknowledgements. This work was supported by the VA Merit Review program (SHG) and National Institutes of Health NINDS R01NS37549 (SHG). Work performed by the Biomedical Mass Spectrometry Center was supported in part by the Cancer Center Support Grant P30CA047904, National Cancer Institute.

1. Larsen CN, Price JS, Wilkinson KD. Substrate binding and catalysis by ubiquitin C-terminal hydrolases: identification of two active site residues. Biochemistry 1996; 35 : 6735-6744.

2. Liu Y, Fallon L, Lashuel HA, Liu Z, Lansbury PT Jr. The UCH-L1 gene encodes two opposing enzymatic activities that affect alpha-synuclein degradation and Parkinson's disease susceptibility. Cell 2002; 111: 209-218.

3. Sakurai M, Sekiguchi M, Zushida K, Yamada K, Nagamine S, Kabuta T et al. Reduction in memory in passive avoidance learning, exploratory behaviour and synaptic plasticity in mice with a spontaneous deletion in the ubiquitin C-terminal hydrolase L1 gene. Eur J Neurosci 2008; 27: 691-701.

4. Gong B, Cao Z, Zheng P, Vitolo OV, Liu S, Staniszewski A et al. Ubiquitin hydrolase Uch-L1 rescues beta-amyloid-induced decreases in synaptic function and contextual memory. Cell 2006; 126: 775-788.

5. Bilguvar K, Tyagi NK, Ozkara C, Tuysuz B, Bakircioglu M, Choi M et al. Recessive loss of function of the neuronal ubiquitin hydrolase UCHL1 leads to early-onset progressive neurodegeneration. Proc Natl Acad Sci USA 2013; 110: 3489-3494.

6. Maraganore DM, Lesnick TG, Elbaz A, Chartier-Harlin MC, Gasser T, Kruger R et al. UCHL1 is a Parkinson's disease susceptibility gene. Ann Neurol 2004; 55: 512-521.

7. Setsuie R, Wada K. The functions of $\mathrm{UCH}-\mathrm{L} 1$ and its relation to neurodegenerative diseases. Neurochem Int 2007; 51: 105-111.

8. Figueiredo-Pereira ME, Rockwell P, Schmidt-Glenewinkel T, Serrano P. Neuroinflammation and J2 prostaglandins: linking impairment of the ubiquitin-proteasome pathway and mitochondria to neurodegeneration. Front Mol Neurosci 2014; 7: 104.

9. Ishii $\mathrm{T}$, Uchida K. Induction of reversible cysteine-targeted protein oxidation by an endogenous electrophile 15-deoxy-delta12,14-prostaglandin J2. Chem Res Toxicol 2004; 17: 1313-1322.

10. Kondo M, Shibata T, Kumagai T, Osawa T, Shibata N, Kobayashi M et al. 15-Deoxy-Delta $(12,14)$-prostaglandin $\mathrm{J}(2)$ : the endogenous electrophile that induces neuronal apoptosis. Proc Natl Acad Sci USA 2002: 99: 7367-7372.

11. Liu H, Li W, Ahmad M, Rose ME, Miller TM, Yu M et al. Increased generation of cyclopentenone prostaglandins after brain ischemia and their role in aggregation of ubiquitinated proteins in neurons. Neurotox Res 2013; 24: 191-204.

12. Wang Z, Aris VM, Ogburn KD, Soteropoulos P, Figueiredo-Pereira ME. Prostaglandin J2 alters pro-survival and pro-death gene expression patterns and $26 \mathrm{~S}$ proteasome assembly in human neuroblastoma cells. J Biol Chem 2006; 281: 21377-21386.

13. Li Z, Melandri F, Berdo I, Jansen M, Hunter L, Wright S et al. Delta12-Prostaglandin J2 inhibits the ubiquitin hydrolase UCH-L1 and elicits ubiquitin-protein aggregation without proteasome inhibition. Biochem Biophys Res Commun 2004; 319: 1171-1180.

14. Liu H, Li W, Ahmad M, Miller TM, Rose ME, Poloyac SM et al. Modification of ubiquitin-Cterminal hydrolase-L1 by cyclopentenone prostaglandins exacerbates hypoxic injury. Neurobiol Dis 2011; 41: 318-328.

15. Koharudin LM, Liu H, Di Maio R, Kodali RB, Graham SH, Gronenborn AM. Cyclopentenone prostaglandin-induced unfolding and aggregation of the Parkinson disease-associated $\mathrm{UCH}$ L1. Proc Natl Acad Sci USA 2010; 107: 6835-6840.

16. Komander D. The emerging complexity of protein ubiquitination. Biochem Soc Trans 2009; 37(Pt 5): 937-953.

17. Choi J, Levey Al, Weintraub ST, Rees HD, Gearing M, Chin LS et al. Oxidative modifications and down-regulation of ubiquitin carboxyl-terminal hydrolase L1 associated with idiopathic Parkinson's and Alzheimer's diseases. J Biol Chem 2004; 279 : 13256-13264.

18. Coulombe J, Gamage P, Gray MT, Zhang M, Tang MY, Woulfe J et al. Loss of UCHL1 promotes age-related degenerative changes in the enteric nervous system. Front Aging Neurosci 2014; 6: 129.

19. Wobst H, Forster S, Laurini C, Sekulla A, Dreiseidler M, Hohfeld J et al. UCHL1 regulates ubiquitination and recycling of the neural cell adhesion molecule NCAM. FEBS J 2012; 279: 4398-4409.

20. Kabuta T, Furuta A, Aoki S, Furuta K, Wada K. Aberrant interaction between Parkinson disease-associated mutant UCH-L1 and the lysosomal receptor for chaperone-mediated autophagy. J Biol Chem 2008; 283: 23731-23738.

21. Meray RK, Lansbury PT Jr. Reversible monoubiquitination regulates the Parkinson diseaseassociated ubiquitin hydrolase UCH-L1. J Biol Chem 2007; 282: 10567-10575.

22. Ahmad M, Dar NJ, Bhat ZS, Hussain A, Shah A, Liu H et al. Inflammation in ischemic stroke: mechanisms, consequences and possible drug targets. CNS Neurol Disord Drug Targets 2014; 13: 1378-1396.

23. Yamamoto Y, Takase K, Kishino J, Fujita M, Okamura N, Sakaeda T et al. Proteomic identification of protein targets for 15-deoxy-Delta(12,14)-prostaglandin J2 in neuronal plasma membrane. PLoS One 2011; 6: e17552.

24. Liu H, Chen J, Li W, Rose ME, Shinde SN, Balasubramani M et al. Protein disulfide isomerase as a novel target for cyclopentenone prostaglandins: implications for hypoxic ischemic injury. FEBS J 2015; 282: 2045-2059.
25. Pande V, Ramos MJ. Molecular recognition of 15-deoxy-delta(12,14)-prostaglandin J2 by nuclear factor-kappa B and other cellular proteins. Bioorg Med Chem Lett 2005; 15 : 4057-4063.

26. Kim HJ, Kim JY, Meng Z, Wang LH, Liu F, Conrads TP et al. 15-deoxy-Delta12,14prostaglandin $\mathrm{J} 2$ inhibits transcriptional activity of estrogen receptor-alpha via covalent modification of DNA-binding domain. Cancer Res 2007; 67: 2595-2602.

27. Ryan AJ, Chen BB, Vennalaganti PR, Henderson FC, Tephly LA, Carter AB et al. 15-deoxy-Delta12,14-prostaglandin J2 impairs phosphatidylcholine synthesis and induces nuclear accumulation of thiol-modified cytidylyltransferase. J Biol Chem 2008; 283: 24628-24640.

28. Soares AF, Nosjean O, Cozzone D, D'Orazio D, Becchi M, Guichardant M et al. Covalent binding of 15-deoxy-delta12,14-prostaglandin J2 to PPARgamma. Biochem Biophys Res Commun 2005; 337: 521-525.

29. Shibata T, Kondo M, Osawa T, Shibata N, Kobayashi M, Uchida K. 15-deoxy-delta 12,14-prostaglandin J2. A prostaglandin D2 metabolite generated during inflammatory processes. J Biol Chem 2002; 277: 10459-10466.

30. Chen YC, Shen SC, Tsai SH. Prostaglandin $D(2)$ and $J(2)$ induce apoptosis in human leukemia cells via activation of the caspase 3 cascade and production of reactive oxygen species. Biochim Biophys Acta 2005; 1743: 291-304.

31. Xiang Z, Lin T, Reeves SA. 15d-PGJ2 induces apoptosis of mouse oligodendrocyte precursor cells. J Neuroinflammation 2007; 4: 18.

32. Ogburn KD, Figueiredo-Pereira ME. Cytoskeleton/endoplasmic reticulum collapse induced by prostaglandin $\mathrm{J} 2$ parallels centrosomal deposition of ubiquitinated protein aggregates. $J$ Biol Chem 2006; 281: 23274-23284.

33. Liu H, Rose ME, Miller TM, Li W, Shinde SN, Pickrell AM et al. COX2-derived primary and cyclopentenone prostaglandins are increased after asphyxial cardiac arrest. Brain Res 2013; 1519: 71-77.

34. Liu H, Li W, Ahmad M, Rose ME, Miller TM, Yu M et al. Increased generation of cyclopentenone prostaglandins after brain ischemia and their role in aggregation of ubiquitinated proteins in neurons. Neurotox Res 2013; 24: 191-204.

35. Huang Q, Figueiredo-Pereira ME. Ubiquitin/proteasome pathway impairment in neurodegeneration: therapeutic implications. Apoptosis 2010; 15: 1292-1311.

36. Ardley HC, Scott GB, Rose SA, Tan NG, Robinson PA. UCH-L1 aggresome formation in response to proteasome impairment indicates a role in inclusion formation in Parkinson's disease. J Neurochem 2004; 90: 379-391.

37. Meller R. The role of the ubiquitin proteasome system in ischemia and ischemic tolerance. Neuroscientist 2009; 15: 243-260.

38. Negre-Salvayre A, Coatrieux C, Ingueneau C, Salvayre R. Advanced lipid peroxidation end products in oxidative damage to proteins. Potential role in diseases and therapeutic prospects for the inhibitors. Br J Pharmacol 2008; 153: 6-20.

39. Erpapazoglou Z, Walker O, Haguenauer-Tsapis R. Versatile roles of k63-linked ubiquitin chains in trafficking. Cells 2014; 3: 1027-1088.

40. Nathan JA, Kim HT, Ting L, Gygi SP, Goldberg AL. Why do cellular proteins linked to K63-polyubiquitin chains not associate with proteasomes? EMBO J 2013; 32: 552-565.

41. Silva GM, Finley D, Vogel C. K63 polyubiquitination is a new modulator of the oxidative stress response. Nat Struct Mol Biol 2015; 22: 116-123.

42. Luchansky SJ, Lansbury Jr PT, Stein RL. Substrate recognition and catalysis by UCH-L1. Biochemistry 2006; 45: 14717-14725.

43. Bishop P, Rubin P, Thomson AR, Rocca D, Henley JM. The ubiquitin C-terminal hydrolase L1 (UCH-L1) C terminus plays a key role in protein stability, but its farnesylation is not required for membrane association in primary neurons. J Biol Chem 2014; 289: 36140-36149.

44. Cartier AE, Djakovic SN, Salehi A, Wilson SM, Masliah E, Patrick GN. Regulation of synaptic structure by ubiquitin C-terminal hydrolase L1. J Neurosci 2009; 29: 7857-7868.

45. Chen F, Sugiura Y, Myers KG, Liu Y, Lin W. Ubiquitin carboxyl-terminal hydrolase L1 is required for maintaining the structure and function of the neuromuscular junction. Proc Natl Acad Sci USA 2010; 107: 1636-1641

46. Jara JH, Genc B, Cox GA, Bohn MC, Roos RP, Macklis JD et al. Corticospinal motor neurons are susceptible to increased ER stress and display profound degeneration in the absence of UCHL1 function. Cereb Cortex 2015; 25: 4259-4272.

47. Zhang M, Cai F, Zhang S, Song W. Overexpression of ubiquitin carboxyl-terminal hydrolase L1 (UCHL1) delays Alzheimer's progression in vivo. Sci Rep 2014; 4: 7298.

48. Shevchenko A, Tomas H, Havlis J, Olsen JV, Mann M. In-gel digestion for mass spectrometric characterization of proteins and proteomes. Nat Protoc 2006; 1 : 2856-2860.

49. Li W, Wu S, Hickey RW, Rose ME, Chen J, Graham SH. Neuronal cyclooxygenase-2 activity and prostaglandins PGE2, PGD2, and PGF2 alpha exacerbate hypoxic neuronal injury in neuron-enriched primary culture. Neurochem Res 2008; 33: 490-499.

50. Liu H, Sarnaik SM, Manole MD, Chen Y, Shinde SN, Li W et al. Increased cytochrome c in rat cerebrospinal fluid after cardiac arrest and its effects on hypoxic neuronal survival. Resuscitation 2012; 83: 1491-1496.

51. Araki K, Araki M, Yamamura K. Targeted integration of DNA using mutant lox sites in embryonic stem cells. Nucleic Acids Res 1997; 25: 868-872.

52. Hughes ED, Qu YY, Genik SJ, Lyons RH, Pacheco CD, Lieberman AP et al. Genetic variation in C57BL/6 ES cell lines and genetic instability in the Bruce4 C57BL/6 ES cell line. Mamm Genome 2007; 18: 549-558. 
53. Araki K, Araki M, Yamamura K. Site-directed integration of the cre gene mediated by Cre recombinase using a combination of mutant lox sites. Nucleic Acids Res 2002; 30 e103.

54. Dymecki SM, Tomasiewicz H. Using Flp-recombinase to characterize expansion of Wnt1-expressing neural progenitors in the mouse. Dev Biol 1998; 201: 57-65.

55. Hosie KA, King AE, Blizzard CA, Vickers JC, Dickson TC. Chronic excitotoxin-induced axon degeneration in a compartmented neuronal culture model. ASN Neuro 2012; 4 pii: 000076 .

56. Fang W, Gao G, Zhao H, Xia Y, Guo X, Li N et al. Role of the Akt/GSK-3beta/CRMP-2 pathway in axon degeneration of dopaminergic neurons resulting from MPP+ toxicity. Brain Res 2015; 1602: 9-19. (c) (i) Cell Death and Disease is an open-access journal published by Nature Publishing Group. This work is licensed under a Creative Commons Attribution 4.0 International License. The images or other third party material in this article are included in the article's Creative Commons license, unless indicated otherwise in the credit line; if the material is not included under the Creative Commons license, users will need to obtain permission from the license holder to reproduce the material. To view a copy of this license, visit http://creativecommons.org/licenses/by/4.0/ 